\title{
NOUVELLES REGHERGHES
}

\author{
SUR
}

\section{MICHEL-ANGE ET SON ENTOURAGE}

Sous ce titre, j'ai réuni quelques documents et quelques observations nouvelles qui ne seront pas inutiles à l'histoire de l'œuvre, de la personne et de l'entourage de Michel-Ange. Ce sont : $1^{\circ}$ une lettre d'Antonio Mini, à qui, comme on le sait, le maître fit don de la Léda; $-2^{\circ}$ une lettre de Cornelia Colonnelli, veuve de Francesco dit Urbino (l'aide dévoué et aimé du grand artiste), écrite peu après la mort de Michel-Ange; $3^{\circ}$ une note sur le tombeau de Philibert de Chalon à Lons-leSaulnier, dont l'esquisse et le devis semblent, d'après une lettre d'Orlando Dei, avoir été soumis à l'examen du grand artiste; $4^{\circ}$ une observation sur Pier Torrigiano, le sculpteur qui, dans un accès de jalousie, déforma pour jamais, d'un coup de poing, le nez de son génial compagnon; - et enfin, en Appendice, une brève histoire des relations entre Michel-Ange et la cour de France.

\section{Lettre d’Antonio Mini a Michel-Ange}

SUR LE TABLEAU ORIGINAL ET LES COPIES DE LA « LÉDA 》

(LyON, 27 JANVIER 1532).

La Léda est certainement, de toutes les œuvres secondaires de Michel-Ange, celle qui a le plus préoccupé les historiens. On se souvient que, lors de la mission diplomatique et militaire à Ferrare qui lui avait été confiée par la république à la fin de juillet 1529, en plein siège de Florence, l'artiste avait promis à Alphonse I $^{\text {er }}$ d'Este d'exécuter une peinture destinée à une des 